\title{
The solubility - intrinsic dissolution rate of diazepam and inclusion complexes diazepam with 2-hydroxypropyl- $\beta$-cyclodextrin
}

\author{
Hadžiabdić J. ${ }^{1}$, Elezović A. ${ }^{1}$, Hadžović S. ${ }^{1}$, Vehabović M. ${ }^{2}$ \\ ${ }^{1}$ Department of Pharmaceutical Technology, Faculty of Pharmacy, University of Sarajevo, Sarajevo, Bosnia and Herzegovina \\ ${ }^{2}$ Bosnalijek d.d., Sarajevo, Bosnia and Herzegovina
}

Email address:

hadziabdicjasmina@yahoo.com(Hadžiabdić J.)

To cite this article:

Hadžiabdić J., Elezović A., Hadžović S., Vehabović M.. The Solubility - Intrinsic Dissolution Rate of Diazepam and Inclusion

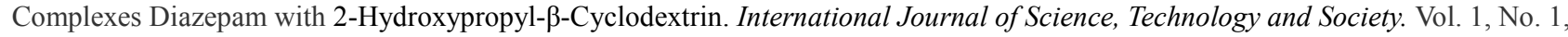
2013, pp. 24-35. doi: 10.11648/j.jists.20130101.14

\begin{abstract}
When the fast absorption of diazepam is needed in order to suppress febrile convulsions and epileptic seizures, the most suitable is intravenous application diazepam. To avoid inappropriate self administration of such diazepam dosage form, orodispersible tablets of diazepam would be the dosage form of choice. Poor solubility of diazepam in water is directly related to its dissolution rate after release from a solid dosage form. Inadequate dissolution rate of diazepam can be the limiting factor for its absorption rate. Inclusion complexation of diazepam with 2-hydroxypropyl- $\beta$-cyclodextrin was carried out to increase the solubility of diazepam at $\mathrm{pH}$ 6.8. Determination of the intrinsic dissolution rate of diazepam as well as complexated diazepam was carried out to predict the absorption rate of diazepam at given $\mathrm{pH}$ value. The solubility of micronized diazepam (particle size $5.4 \mu \mathrm{m}$ ) at $\mathrm{pH} 6.8$, was $0.043 \mathrm{mg} \mathrm{mL}^{-1}$, while the solubility of non-micronized diazepam (particle size $414.8 \mu \mathrm{m}$ ) at the same $\mathrm{pH}$ was $0.036 \mathrm{mg} \mathrm{mL}^{-1}$. Inclusion complexation of diazepam with 2 -hydroxypropyl- $\beta$-cyclodextrin resulted in increased solubility of diazepam. One mole of 2-hydroxypropyl- $\beta$-cyclodextrin increased the solubility of micronized diazepam 6.82 fold, while two moles of 2-hydroxypropyl- $\beta$-cyclodextrin increased the solubility of diazepam 12.55 fold. Given that the values of intrinsic dissolution rates (IDR) of micronized diazepam, non-micronized diazepam and inclusion complex D: 2-HP- $\beta$-CD 1:1 were less than $0.1 \mathrm{mg} \mathrm{min}^{-1} \mathrm{~cm}^{-2}$, the absorption of diazepam dissolution would be the rate limiting step to absorption, while the inclusion complex D: 2-HP- $\beta$-CD 1:2 where an IDR value was greater than $0.1 \mathrm{mg} \mathrm{min} \mathrm{m} \mathrm{cm}^{-2}$ at $\mathrm{pH} 6.8$, suggested that its dissolution might be the rate-limiting step to absorption. Hydroxypropyl- $\beta$-cyclodextrin increased the solubility of diazepam at $\mathrm{pH} 6.8$, thus increasing the dissolution rate and causing faster absorption of diazepam at $\mathrm{pH} 6.8$.
\end{abstract}

Keywords: Diazepam, 2-Hydroxypropyl- $\beta$-Cyclodextrin, Solubility, Intrinsic Dissolution Rate

\section{Introduction}

Diazepam, as the most representative benzodiazepine, is widely used as anticonvulsant, anxiolytic, sedative agent, hypnotic, muscle relaxant and is also very useful in suppressing febrile and epileptic convulsions (Fig. 1). Rapid termination of febrile convulsions and epileptic seizures requires rapid absorption of diazepam [1,2]. Although intravenous therapy is the most rapid way to suppress febrile and epileptic convulsions, this route of drug administration requires e.g. qualified medical personnel [3]. Alternatively, if diazepam is formulated as orodispersible tablet, it could be an alternative to parenteral therapy enabling patient for self-administration, even without the aid of water in a situation where the onset of convulsion is anticipated. Rapid absorption requires rapid dissolution, which depends on greater aqueous solubility. According to the biopharmaceutics classification cystem (BCS), diazepam belongs in the class II drugs. Class II compounds comprise relatively lipophylic and water-insoluble drugs (i.e. the saturation solubility of the drug in the aqueous fluid, $\mathrm{C}_{\mathrm{s}} \leq 0.1$ $\mathrm{mg} \mathrm{mL}^{-1}$ ) that, when dissolved, are well absorbed from gastrointestinal (GI) tract. If aqueous solubility of a drug is below $0.1-0.05 \mathrm{mg} \mathrm{mL}^{-1}$, the dissolution of the drug particles will be slow, thus limiting the dissolution rate. Low $\mathrm{C}_{\mathrm{s}}$ hampers drug's dissolution. 


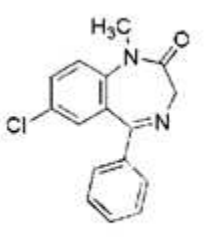

a)

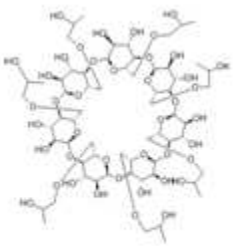

b)

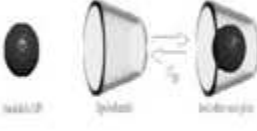

Figure 1. The chemical structures of a) diazepam b) 2-hydroxypropyl- $\beta$-cyclodextrin c) inclusion complexation.

Water-soluble cyclodextrin complexes of these drugs will increase their apparent $\mathrm{C}_{\mathrm{s}}$ value, thus facilitating dissolution, leading later to the enhanced oral bioavailability [4,5].

Cyclodextrins form a group of structurally related oligosaccharides with cylinder-shaped cavities that have the capacity to form inclusion complex with many drugs by taking a whole drug, or a part of it, into their hydrophobic cavity (Fig. 1). Hydroxypropyl- $\beta$-cyclodextrin has been considered to be the most accepted representative of hydroxyalkylated derivatives as hydrophilic drug carrier, because of its amorphousness, higher water solubility, solubilizing power and lower toxicity compared to the parent $\beta$-cyclodextrin and other hydrophilic derivatives of $\beta$-cyclodextrin (Fig. 1). Complexation with cyclodextrins can enhance the solubility, dissolution rate and bioavailability of poorly water solubile drugs [6,7]. The pH-solubility profile of the drug is determined at $37{ }^{\circ} \mathrm{C}$ $\pm 1{ }^{\circ} \mathrm{C}$ in aqueous medium in the $\mathrm{pH}$ range of $1.0-7.5$. The solubility class is obtained by calculating the volume of solution necessary to dissolve the greatest dose of the drug over all $\mathrm{pH}$ ranges evaluated.

According to the BCS, a drug substance is considered highly soluble in $250 \mathrm{~mL}$ or less of aqueous medium over the $\mathrm{pH}$ range [8,9]. Because dissolution depends on the solubility of the drug and absorption depends on the intestinal permeability, these are the main factors that determine the bioavailability of an orally administered solid formulation. The BCS defines tree dimensionless numbers, dose number $\left(D_{0}\right)$, dissolution number $\left(D_{n}\right)$ and absorption number $\left(A_{n}\right)$, to characterize drug substances. These numbers are combinations of physicochemical and physiological parameters and represent the most fundamental view of GI drug absorption. The dose number, $\mathrm{D}_{\mathrm{o}}$, is defined as the ratio of dose concentration to drug solubility (1).

$$
D_{o}=\frac{M / V_{o}}{C_{s}}
$$

where is:

$\mathrm{M}$ - the dose of administered $\operatorname{drug}(\mathrm{mg})$,

$\mathrm{V}_{\mathrm{o}}$ - the volume of water taken with dose which is generally set to be $250 \mathrm{~mL}$,

$\mathrm{C}_{\mathrm{s}}$ - the saturation solubility $\left(\mathrm{mg} \mathrm{mL}^{-1}\right)$ [10-12].

One alternative for determining solubility is the intrinsic dissolution test, where the solubility class of a drug is determined by the value of the intrinsic dissolution rate (IDR). IDR determinations can provide an important insight into the dissolution behavior of a drug in physiological conditions. This test has a place in the screening process of drug candidates for further development [13]. The feasibility of using IDR as opposed to saturation solubility data to place drugs in a BCS class as in vivo drug dissolution is a dynamic rate controlled process, rather than an equilibrium process [14].

The aim of this paper was to form inclusion complexes of diazepam with 2-HP- $\beta-C D$ which would increase the solubility of diazepam in water and improve the intrinsic dissolution rate of diazepam. Diazepam is used in the suppression of febrile convulsions and epileptic seizures, requiring rapid absorption. In order to bypass unpleasant and dependent application of intravenous administration of diazepam, preformulation studies of two inclusion complexes as potential raw materials that would be integral components of alternative dosage forms of diazepam (orodisperzible tablets) were performed in this study. The intrinsic dissolution rate of diazepam and its inclusion complexes at $\mathrm{pH} 6.8$ (saliva) were determined and sought to predict the absorption of diazepam.

\section{Materials and Methods}

\subsection{Materials}

Diazepam(7-chloro-1,3-dihydro-1-methyl-5-phenyl-2H-1 ,4-benzodiazepin-2-one) (F.I.S. - Fabbrica Italiana Sintetici, Italy), Diazepam (Selectchemie AG, Switzerland), Acidum hydrochloricum fumans, 37\%, pro analysi, (Merck KgaA, Germany), Sodium dihydrogen phosphate dihydrate (Merck KGaA, Germany), Disodium hydrogen phosphate (Merck KGaA, Germany), Potassium dihydrogen phosphate (Merck KgaA, Germany), 2-Hydroxypropyl- $\beta$-cyclodextrin $\left(\right.$ Cavasol $^{\circledR}$ W7 HP, DS 6.8, $\mathrm{M}_{\mathrm{r}} \sim 1410 \mathrm{~g} \mathrm{~mol}^{-1}$, ISP A.G., Germany), Methanol, p. a., (Merck KGaA, Germany), Ethanol, 96\% v/v (Sigma-Aldrich GmbH, Germany), Metanol, 99.90\%, p. a., HPLC purity (Merck KGaA, Germany), N, N-dimethylformamide (chromatographically pure min. 99\%) (Merck KGaA, Germany).

\subsection{Determination of Particle Size Distribution}

To determine the particle size distribution of tested powders laser diffractometer Mastersizer 2000 was used, with the unit for dry sample dispersion Scirocco 2000 (Malvern Instruments, Great Britain). The test sample was transferred into a glass vial, taking $70 \%$ to $80 \%$ of its volume. A glass vials were turned for 20 seconds to the left side and 20 seconds to the right, in order to obtain a more homogenous sample before recording. Immediately after mixing, using a spatula, approximately one gram of sample (depending on the volume of powder) was transferred into the dispersive unit. In dispersion unit the sample was 
dispersed in airflow and compressor - under constant conditions, and was transmitted to the optical unit on the recording beam lasers. In the optical unit (in the recording zone) the sample remained for 12 seconds during which the particles rolled on its axis. Laser beam was shooting it about 12000 times. Laser diffraction method, the most common method for the analysis of particle size, was used to determine particle size distribution of diazepam (D1 and D2), inclusion complexes of diazepam and $2-\mathrm{HP}-\beta-\mathrm{CD}$ in the molar ratios of $1: 1$ and 1:2. Using this method it is possible to determine the size of powder particles in the range of 0.05 $\mu \mathrm{m}-3500 \mu \mathrm{m}$. The average diameter of the particles and the average particle size distribution were obtained by measuring the intensity of diffracted light and calculating the total intensity of scattered light. The angle of diffraction of laser beams scattered from the particles of sample is inversely proportional to the particle size [15]. The individual measurements of particle size distribution were repeated five times.

\subsection{Phase Solubility Studies}

Determination of solubility of two powder samples of diazepam (D1 - F.I.S. - Fabbrica Italiana Sintetici, Italy and D2 - Selectchemie AG, Switzerland) in water was conducted by sampling of aqueous solutions of diazepam in selected time intervals during 48 hours (Table 1) [16,17]. Solubility measurements and the determination of saturation concentrations were carried out by adding excess amounts of diazepam and inclusion complexes to water and phosphate buffer solutions ( $\mathrm{pH}$ meter SevenMulti ${ }^{\mathrm{TM}} \mathrm{S} 47-\mathrm{K}$, Mettler Toledo GmbH, Germany). Solubility measurements and the determination of saturation concentrations of physical mixtures were carried out by addition of excess amounts of physical mixtures to water $[9,16]$. As a medium for solubilization of diazepam and inclusion complexes the chloride buffer solution, as an acidic medium that simulates gastric fluid without enzymes, and phosphate buffer solutions, simulating intestinal fluid without enzymes, were selected with $\mathrm{pH}$ values ranging from 1.2 to $7.4[8,9]$. The powders of diazepam/physical mixtures/inclusion complexes were added (Analytical balance type XS 205DU/A, Mettler Toledo GmbH, Germany) to dark, glass flasks $(50 \mathrm{~mL})$ (Tables $2,3,5,6$.). The samples were shaken at $200 \mathrm{rpm} / \mathrm{min}$, during 24 hours on thermostated shaking bath (BDL, Type: GFL 1083, Czech Republic), to reach equilibrium, at $37{ }^{\circ} \mathrm{C} \pm 0.1{ }^{\circ} \mathrm{C}$. During testing it was necessary to provide sink conditions i.e. the conditions where the total concentration of dissolved active substance should not be higher than $10 \%-15 \%$ of its saturated concentration[18]. Undissolved substance was visualized before and after the achievement of equilibrium. After mixing, the solutions were left for 24 hours at room temperature in order to achieve equilibrium between the dissolved and undissolved diazepam in solution (saturated aqueous solution)[17]. Samples (all suspensions) were filtered through a $0.2 \mu \mathrm{m}$ pore size membrane filter
(Cellulose acetate filter, Sartorius, Germany). The concentrations of dissolved diazepam, physical mixtures and inclusion complexes in clear water solutions and phosphate buffer solutions were determined by absorption spectroscopy using Varian Cary 50 UV-VIS spectrophotometer (Varian, Inc., USA) at $230 \mathrm{~nm}$ (for phosphate buffer solutions of $\mathrm{pH} 6.8$ and 7.4) and $241 \mathrm{~nm}$ (for water solutions and the other phosphate buffer solutions) in $0.1 \mathrm{~mol} \mathrm{~L}^{-1}$ hydrochloric acid (which was previously used to develop the calibration curve: concentration range: 2.0 $10.0 \mathrm{mg} \mathrm{L}^{-1}$, correlation coefficient $\left.\mathrm{R}^{2}=0.9999\right)$. All experiments were carried out in triplicate $(n=3)$ and the results are presented as the mean values (Tables 2, 3, 5, 6).

\subsection{Preparation of Inclusion Complexes of Diazepam with 2-HP- $\beta-C D$ by Solvent Evaporation}

Binary systems of diazepam and 2-HP- $\beta-C D$ were prepared in the molar ratios of $1: 1$ and $1: 2$. For preparation of the inclusion complexes by evaporation method, methanol was used as a solvent for diazepam and $2-H P-\beta-C D[19,20]$. Diazepam is freely soluble in methanol ( $1 \mathrm{~g}$ dissolving in $5 \mathrm{~mL}$ methanol). For dissolving one gram of 2 -HP- $\beta-C D$, it was necessary to take $2 \mathrm{~mL}$ of methanol. Diazepam and 2-HP- $\beta-C D$ were separately dissolved in methanol on ultrasonic bath (Sonorex Digitec DT $512 \mathrm{H}$, Bandelin, GmbH, Germany) for 15 minutes at room temperature (at $25^{\circ} \mathrm{C}$ ). A minimum volume of methanol, for achieving the unsaturated solution, was used in order to dissolve the substances. To the clear methanolic solution of diazepam the methanolic solution of 2-HP- $\beta-C D$ was added, and the solution was homogeneously mixed on magnetic stirrer, C - MAG HP 7 (IKA ${ }^{\circledR}$, Werke GmbH \& Co.KG, Germany), for 30 minutes. The solvent was evaporated from methanolic solution of the mixture of diazepam and 2-HP- $\beta-C D$ on Rotavapor R-205 (Buchi, Switzerland). The water temperature of rotavapor bath was set to $40{ }^{\circ} \mathrm{C} \pm 0.5$ ${ }^{\circ} \mathrm{C}$. The given temperature was lower than the boiling point of methanol $\left(\mathrm{t}_{\mathrm{b} \text { (methanol) }}=65^{\circ} \mathrm{C}\right)$. Evaporation of methanol was carried out under reduced pressure of 337 mbar. The solvent was evaporated at $120 \mathrm{rpm} / \mathrm{min}$. Time of evaporation of solvent depended on its volume (i.e. the mass of the sample). During the evaporation of methanol in the sample with diazepam and 2-HP- $\beta-C D$, a white layer of solid inclusion complex formed. The samples were subjected to drying for a period of 6 hours in vacuum oven VD 23 (Binder, USA) at $40{ }^{\circ} \mathrm{C} \pm 0.5^{\circ} \mathrm{C}$ and at $75^{\circ} \mathrm{C} \pm 0.5^{\circ} \mathrm{C}$, at pressure of $6 \pm 2$ mbar. After drying in vacuum oven a white, shiny crystals of newly formed compound were obtained. Completely dry samples were sieved through sieve No. 20 (WS Tyler ${ }^{\circledR}$, Ohio, USA) and stored in dark glass bottles until analysis. Physical mixture of diazepam $\left(\mathrm{M}_{\mathrm{r}}=284.75 \mathrm{~g}\right.$ $\left.\mathrm{mol}^{-1}\right)$ and 2-HP- $\beta-\mathrm{CD}\left(\mathrm{M}_{\mathrm{r}} \sim 1410 \mathrm{~g} \mathrm{~mol}^{-1}\right)$ was prepared by mixing diazepam and $2-\mathrm{HP}-\beta-\mathrm{CD}$ without applying pressure. The required quantities of diazepam and $2-\mathrm{HP}-\beta-\mathrm{CD}$ were taken to glass mortar and mixed for 30 minutes. 


\subsection{Determination of Residual Methanol in Inclusion Complexes of Diazepam and 2-HP- $\beta-C D$}

Methanol, which was used for preparing inclusion complexes, is classified as a solvent of class 2 , whose use in pharmaceutical products, due to its toxicity, should be limited because of the safety of patient[21]. Methanol residues in inclusion complexes were determined by gas chromatography with gas chromatograph Perkin Elmer Clarus 500 with FID Turbomatrix HS-40 PE detector (Perkin Elmer, Italy).

Conditions of chromatography: The capillary column SUPELCO Fused silica OVI-G43, length $30 \mathrm{~m}$, diameter $0.53 \mathrm{~mm}$, particle size of $3 \mu \mathrm{m}$ was used as a stationary phase. Column filling was a mixture of $6 \%$ and $96 \%$ dimethylsiloxane. The analysis was carried out with nitrogen $\left(\mathrm{N}_{2}\right)$ as a carrier gas. Testing was performed for inclusion complex D : 2-HP- $\beta-C D$ 1:1 and D : 2-HP- $\beta-C D$ 1:2, subjected to drying at $40{ }^{\circ} \mathrm{C} \mathrm{i} 75^{\circ} \mathrm{C}$, in the vacuum oven.

Standard solution: Methanol $(62.5 \mathrm{mg})$ was weighed in a flask of $50 \mathrm{~mL}$ containing $25 \mathrm{~mL}$ of $\mathrm{N}$, N-dimethylformamide, and filled to the mark. The standard solution $(2.5 \mathrm{~mL})$ was pipetted in $25 \mathrm{~mL}$ flask containing 10 $\mathrm{mL}$ of $\mathrm{N}, \mathrm{N}$-dimethylformamide and filled to the mark. The standard solution ( $4 \mathrm{~mL}$ ) was added to the head space vial and analyzed in duplicate.

Blank solution: N, N-dimethylformamide (4 mL) was pipetted in the head space vial and gas chromatography was carried out in triplicate.

Sample solution: The sample was weighed $(1000 \mathrm{mg})$ in the head space vial, and $4 \mathrm{~mL}$ of $\mathrm{N}, \mathrm{N}$-dimethylformamide were added, and the tested sample was dissolved by shaking.

Procedure: Chromatography was performed on standard solutions and sample solutions and the chromatograms were recorded.

Calculation of residual solvent in the sample: The content of residual solvent (methanol) in the samples was calculated using the following equation:

$$
\text { content of methanol }(\mathrm{ppm})=\frac{P_{p} \cdot m_{s t} \cdot C \cdot d_{p} \cdot 10.000}{P_{s t} \cdot V_{s t} \cdot m_{p} \cdot d_{s t}}
$$

where is:

$P_{p}$ - peak area of residual solvent in the chromatogram of the sample solution,

$P_{s t}$ - peak area of residual solvent in the chromatogram of the standard solution,

$m_{p}$ - weight of test substance solution of sample (mg),

$V_{s t}$ - volume of standard solution,

$m_{s t}$ - weight of residual solvent standard solution $(\mathrm{mg})$,

$C$ - content of residual solvent standard substance (\%),

$d_{p}$ - dilution of the sample solution,

$d_{s t}$ - dilution of the standard solution.

According to the ICH guidelines [21] limited concentration (ppm) of residual solvent class 2 (methanol) was calculated according to (3) for the case when the applied dose of drug was not more than $10 \mathrm{~g}$ :

$$
\text { concentration }(\mathrm{ppm})=\frac{1000 \cdot P D E}{\text { dose }}
$$

PDE - permitted daily exposure was given in $\mathrm{mg} \mathrm{day}^{-1}$, while the dose was given in $\mathrm{g} \mathrm{day}^{-1}$.

\subsection{Determination of Intrinsic Dissolution Rate of Diazepam and Inclusion Complexes of Diazepam with 2-HP-B-CD Using a Rotating Disk Method}

Determination of the intrinsic dissolution rate (dissolution flow - IDR or $j$ ) was performed on four samples, using the rotating disk method [22]. Testing was conducted on VanKel VK7025 Varian (Varian Inc., USA) dissolution apparatus fitted with Wood's intrinsic dissolution die. The two raw materials of diazepam were used: micronized diazepam (D1) and non-micronized diazepam (D2), as well as inclusion complexes D: 2 -HP- $\beta-C D$ 1:1 and D: $2-H P-\beta-C D ~ 1: 2$. Each sample tested was weighed six times per $200 \mathrm{mg}$. Disc (matrix, die) was attached to a smooth polished metal plate. Powders were transferred to the die and compressed directly in it using the steel punches and laboratory hydraulic press EQ-YLJ-24T (MTI Corporation, USA). For compression of powders, the hydraulic press was used with applied compression force of $10 \mathrm{kN}$, with the pressure duration of 5 seconds. After compression, the metal plate was separated from the disc. The comprimates obtained were compact, smooth, and of satisfactory hardness. Discs with prepared comprimates (drug pellets) were attached directly to the carriers. Together with the carrier, comprimates were immersed in a container with the dissolution medium and at a constant distance of the drug disk from the bottom of the dissolution vessel (1.5 inch), rotated at a speed of 100 $\mathrm{rpm} / \mathrm{min}$ releasing the substance in the solution. Sample comprimates in the die with the area of $0.5 \mathrm{~cm}^{2}$ (the inner diameter of the disc), were placed so that only one surface of samples was in contact with the dissolution medium. The phosphate buffer solution of $\mathrm{pH} 6.8$, in a volume of $900 \mathrm{~mL}$ at $37^{\circ} \mathrm{C} \pm 0.5^{\circ} \mathrm{C}$ was used as the dissolution medium. Prior to determining the content of dissolved diazepam from the surface of comprimates, the samples were automatically filtered through a filter with the pore size of $0.35 \mu \mathrm{m}$ (Quality Lab Accessorius LLC, Varian, Inc., USA). Samples were collected automatically, directly from the dissolution container, every five minutes of an hour, through a system of tubes using peristaltic pumps. During the test, the flow of solvent, in direct contact with the surface drug comprimates, needed to be laminar. The flow of fresh solvent passing over the surface of the solid sample should be constant during the entire test or to be controlled, in order for the test to be repeatable. If particles became small, it would not be possible to control the contact area $[10,13,14]$. In tested samples, the released diazepam was assayed from the constant surface in predetermined, already mentioned, time intervals. Quantification of dissolved diazepam was carried out by external standard method on UV-VIS 
spectrophotometer Varian Cary 50 (Varian Inc., USA) at the wavelength of $230 \mathrm{~nm}$.

Solution of diazepam standard: The diazepam standard of $10.1145 \mathrm{mg}$ was dissolved (diazepam content was $99.50 \%$ ) in a volumetric flask of $100 \mathrm{~mL}$ in $1 \mathrm{~mL}$ of methanol. The solution was filled to the mark with phosphate buffer solution pH 6.8 (solution A, $\mathrm{c}_{\text {(solution of diazepam standard) }}=10.0639$ $\mathrm{mg} \mathrm{mL} \mathrm{m}^{-1}$ ). Volume of $1 \mathrm{~mL}$ of solution A was diluted in a volumetric flask with $25 \mathrm{~mL}$ of phosphate buffer solution $\mathrm{pH}$ $6.8\left(\mathrm{c}_{\text {(solution of diazepam standard })}=4.026 \mathrm{mg} \mathrm{mL}^{-1}\right)$. Intrinsic dissolution rate was measured under the conditions where the surface of solid was kept constant in the vessel in which it rotated, and the results of intrinsic dissolution rate were expressed as $\mathrm{mg} \mathrm{min}^{-1} \mathrm{~cm}^{-2}$. IDR was calculated using linear regression analysis, from the slope of the regression line according to the following equation:

$$
j=V \cdot \frac{d c}{d t} \cdot \frac{1}{A}
$$

where:

$j$ - intrinsic dissolution rate or dissolution flow ( $\mathrm{mg} \mathrm{min}^{-1}$ $\mathrm{cm}^{-2}$,

$V$ - volume of the dissolution medium $(\mathrm{mL})$,

$c$ - concentration of dissolved drug in the medium (mg $\left.\mathrm{mL}^{-1}\right)$

$t$ - time ( $\mathrm{min})$,

$A$ - area of sample disk $\left(\mathrm{cm}^{2}\right)[10,13,23]$.

The IDR is a key indicator of the potential bioavailability

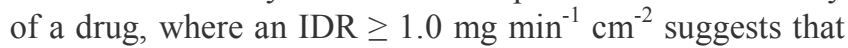

drug dissolution will not be the rate-limiting step to absorption, whilst an IDR $\leq 0.1 \mathrm{mg} \mathrm{min}^{-1} \mathrm{~cm}^{-2}$ suggests that drug dissolution will be the rate-limiting step to absorption. An intermediate value suggests that drug dissolution may be the rate-limiting step to absorption[13].

\section{Results and Discussion}

\subsection{Determination of Particle Size Distribution of Diazepam}

Results of particle size distribution of the two powder samples of diazepam were shown as average values of measurements (Table 1) and graphically presented (Fig. 2 and 3) in histogram form. The $\mathrm{x}$-axis of the histogram represented data on particle size $(\mu \mathrm{m})$, while the $y$-axis was the percentage of representation of certain volume fraction (\%). The $\mathrm{x}$-axis of the histogram length square referred to the interval dimension of particles, and the y-axis length of the square histogram referred to the percentage representation of the particle size.

According to the results $90 \%$ of the particles of diazepam, D1, were less than $5.4 \mu \mathrm{m}$, while $90 \%$ of the particles of diazepam, D2, were less than $414.8 \mu \mathrm{m}$.

Based on the analysis of particle size, it was determined that the sample D1, had smaller particle size and higher specific surface area. It was classified as the micronized powder compared to D2, which was non-micronized powder.

Table 1. Particle size distribution of diazepam

\begin{tabular}{cccc}
\hline \multirow{2}{*}{ Samples } & Specific surface area & \multicolumn{2}{c}{ Particle size distribution of diazepam } \\
\cline { 3 - 3 } & $\left(\mathbf{m}^{\left.\mathbf{2} \mathbf{g}^{-1}\right)}\right.$ & $\mathrm{d}(0.1)^{\mathrm{a}} \mu \mathrm{m}$ & $\mathrm{d}(0.5)^{\mathrm{b}} \mu \mathrm{m}$ \\
\hline diazepam (D1) & 2.73 & 1.206 & 2.645 \\
diazepam (D2) & 0.28 & 8.483 & 5.391 \\
\hline
\end{tabular}

a. $\mathrm{d}(0.1) \mu \mathrm{m}-10 \%$ of particles of the sample is less than the specified value, b. $d(0.5) \mu \mathrm{m}-50 \%$ of particles of the sample is less than the specified value,

c. $d(0.9) \mu \mathrm{m}-90 \%$ of particles of the sample is less than the specified value.

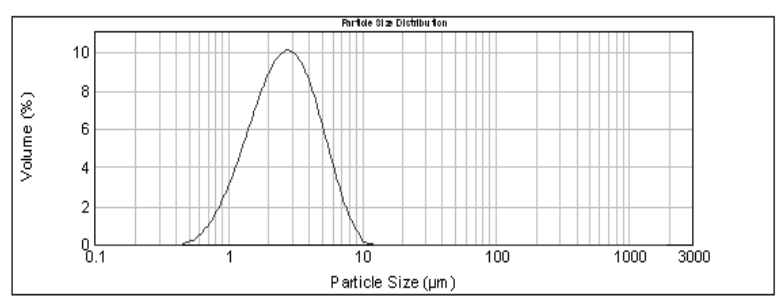

Figure 2. Particle size distribution of diazepam (D1).

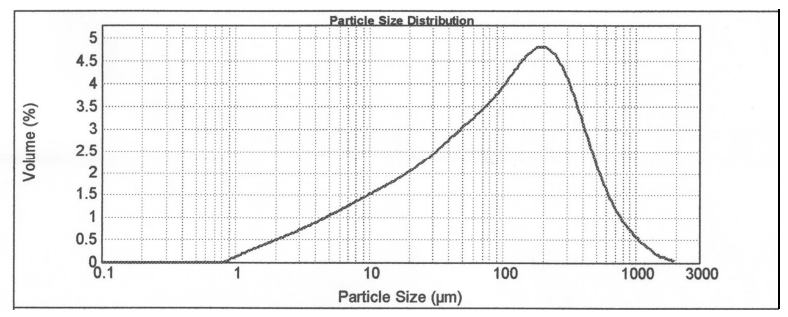

Figure 3. Particle size distribution of diazepam (D2).

\subsection{Solubility Study of Diazepam in Water}

The results of the diazepam solubility in water were listed in Table 2 and Fig. 4.

The solubility of diazepam in water was affected by the particle size. Micronized diazepam, D1 has a higher solubility in water regardin on non-micronized powder diazepam, D2. Both raw material of diazepam are hydrophobic powders. Hydrophobia is expressive of micronized diazepam (D1), which in contact with water exhibits poor wettability. In our case, hydrophobicity did not affect the reduction of diazepam solubility in water. Micronized diazepam has a much higher specific surface area of particles (Table 1) in relation to non-micronized powder. The effect of particle size, their shape and surface characteristics of the formulation, particularly significant in poorly soluble substances. 
Table 2. Diazepam solubility in water determined within 24 hours and after 48 hours, at 37 oC \pm 0.1 oC $(n=3)$

\begin{tabular}{|c|c|c|c|c|}
\hline $\begin{array}{l}\text { Time } \\
\text { (hour) }\end{array}$ & $A^{d}$ & $\begin{array}{c}\mathrm{D1}^{\mathrm{e}} \\
(\mathrm{mg} \mathrm{mL}-1 \pm \times 10-4)\end{array}$ & $A^{d}$ & $\begin{array}{c}\mathrm{D2}^{\mathrm{e}} \\
(\mathrm{mg} \mathrm{mL}-1 \pm \times 10-4)\end{array}$ \\
\hline 1. & 0.4512 & $0.0453 \pm 1.27$ & 0.3411 & $0.0320 \pm 2.18$ \\
\hline 2. & 0.5080 & $0.0482 \pm 2.99$ & 0.3665 & $0.0345 \pm 3.28$ \\
\hline 15. & 0.5397 & $0.0512 \pm 4.30$ & 0.4412 & $0.0415 \pm 1.54$ \\
\hline 19. & 0.5372 & $0.0510 \pm 1.84$ & 0.4356 & $0.0413 \pm 1.86$ \\
\hline 20. & 0.5370 & $0.0510 \pm 1.53$ & 0.4433 & $0.0420 \pm 4.70$ \\
\hline 21. & 0.5350 & $0.0508 \pm 2.29$ & 0.4517 & $0.0430 \pm 2.24$ \\
\hline 23. & 0.5276 & $0.0500 \pm 2.10$ & 0.4495 & $0.0420 \pm 3.36$ \\
\hline 24. & 0.5370 & $0.0510 \pm 1.28$ & 0.4427 & $0.0418 \pm 1.17$ \\
\hline 48. & 0.5368 & $0.0510 \pm 2.55$ & 0.4440 & $0.0420 \pm 1.76$ \\
\hline
\end{tabular}

d. Absorbance; e. Concentration of diazepama $\left(\mathrm{mg} \mathrm{mL}^{-1}\right)$ : D1 - particle size of diazepam $5.4 \mu \mathrm{m}$, D2 - partice size of diazepam $414.8 \mu \mathrm{m}$.

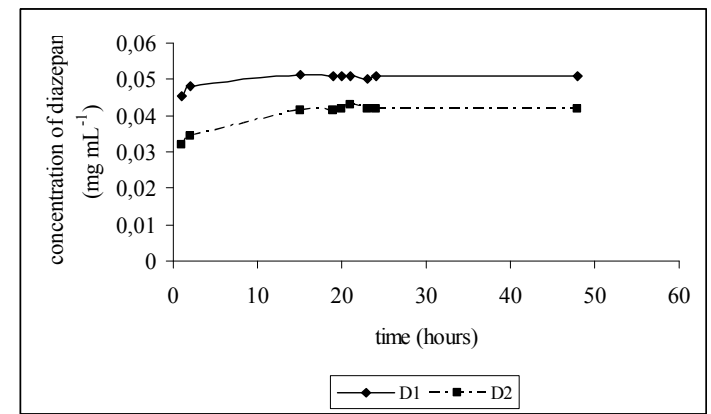

Figure 4. Concentration of diazepam depending of time.

\subsection{Diazepam Solubility in Phosphate Buffer Solutions}

The results for diazepam solubility at various $\mathrm{pH}$ values of phosphate buffer solutions were summarized in Table 3. and
Fig. 5.

Diazepam solubility increases with decreasing $\mathrm{pH}$ of the media being more soluble in acidic, compared to the neutral medium.

Results of the solubility testing of diazepam in chloride buffer and phosphate buffer solutions indicate that diazepam, in the media of $\mathrm{pH} 3.5$ to 7.4 , was practically insoluble, while at the media $\mathrm{pH}$ of 2.5 to 1.2 was very slightly soluble to slightly soluble. At the $\mathrm{pH} 2.0$, the solubility of diazepam (D1) increased 29.5 fold and at the $\mathrm{pH}$ value of 1.2 to 105.9 fold. During the dissolution, weak bases or acids partially dissociate, and their solubility in bodily fluids is strongly dependent on the acidity of the media. Only the non ionized substance will be available for the absorption.

Tabela 3. Solubility of diazepam in buffer solutions at $37^{\circ} \mathrm{C} \pm 0.1 \mathrm{oC}(n=3)$

\begin{tabular}{|c|c|c|c|c|}
\hline$p^{f}$ & $A^{d}$ & $\begin{array}{c}\mathrm{D1}^{\mathrm{e}} \\
\left(\mathrm{mg} \mathrm{mL}^{-1} \pm \times 10^{-4}\right)\end{array}$ & $\mathbf{A}^{\mathrm{d}}$ & $\begin{array}{c}\mathrm{D}^{\mathrm{e}} \\
\left(\mathrm{mg} \mathrm{mL}^{-1} \pm \times 10^{-4}\right) \\
\end{array}$ \\
\hline 1.2 & 0.568 & $5.402 \pm 2.92$ & 0.509 & $4.8212 \pm 3.56$ \\
\hline 2.0 & 0.591 & $1.5060 \pm 1.02$ & 0.569 & $1.0667 \pm 0.54$ \\
\hline 2.5 & 0.775 & $0.3987 \pm 0.73$ & 0.321 & $0.2967 \pm 0.14$ \\
\hline 3.5 & 0.452 & $0.0925 \pm 0.08$ & 0.341 & $0.0633 \pm 0.02$ \\
\hline 4.5 & 0.558 & $0.0523 \pm 0.06$ & 0.457 & $0.0433 \pm 0.03$ \\
\hline 5.5 & 0.498 & $0.0491 \pm 0.03$ & 0.420 & $0.0400 \pm 0.03$ \\
\hline 6.0 & 0.502 & $0.0488 \pm 0.02$ & 0.410 & $0.0387 \pm 0.02$ \\
\hline 6.8 & 0.460 & $0.0426 \pm 0.02$ & 0.699 & $0.0358 \pm 0.02$ \\
\hline 7.4 & 0.378 & $0.0385 \pm 0.01$ & 0.356 & $0.0333 \pm 0.03$ \\
\hline
\end{tabular}

f. $\mathrm{pH}$ values of chloride buffers and phosphate buffers.

Concentration of non ionized form will depend on the $\mathrm{pH}$ of the environment [24,25]. Diazepam is weakly dissociating base with $\mathrm{pKa}$ value of 3.3. Lower $\mathrm{pH}$ values increase the dissociation of diazepam. Diazepam (D1) in phosphate buffer solution $\mathrm{pH} 6.8$ was more than $99.94 \%$ in the non ionized form or less than $0.06 \%$, in dissociated form. Since the absorption rate of the active substance dissolved in biological fluids depends on the concentration of non ionized lipophilic part, and the concentration of non ionized form of the active substance at the site of absorption depends on the degree of ionization and the $\mathrm{pH}$ at the site of absorption, based on the results we could expect good absorption of diazepam at $\mathrm{pH} 6.8$ and 7.4, respectively, via the buccal mucosa. In neutral $\mathrm{pH}$, solubility of diazepam (D1) was $0.0385 \mathrm{mg} \mathrm{mL}^{-1}$ which could be considered as the solubility of its non ionized form. In this way, one could only approximate prediction of absorption, given that it was almost impossible for each drug molecule to predict 
absorption.

Diazepam is poorly soluble in water. The substance is considered to be poorly soluble if its highest dose is soluble in a larger volume of $250 \mathrm{~mL}$ of water or a suitable aqueous medium whose $\mathrm{pH}$ varies in the range of $\mathrm{pH}$ values of the GI tract ( $\mathrm{pH} 1-7.5)$ at $37^{\circ} \mathrm{C}[8]$. Very poorly soluble substances, such as diazepam, which have very low therapeutic doses, should be completely dissolved under physiological conditions.

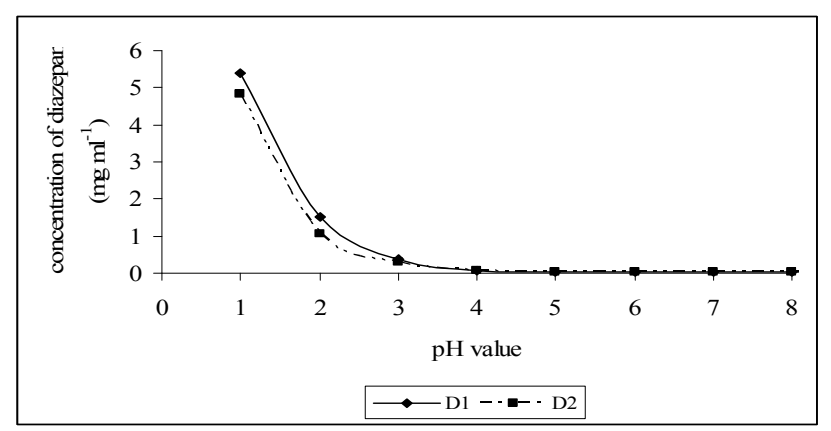

Figure 5. Solubility change of micronized diazepam (D1) and non-micronized diazepam (D2) with regards to the $\mathrm{pH}$ values of phosphate buffer solutions.

Probability of bioavailability problems requires consideration of both drug dose and its solubility, as well as, permeability. The absorption of diazepam through the GI tract, administered in therapeutic doses of $5 \mathrm{mg}$ and $10 \mathrm{mg}$ could be represented using a dose number $\left(D_{0}\right)$, which was shown in Table 4.

Table 4. The calculated parameters for single dose of diazepam

\begin{tabular}{ccccc}
\hline Drug & Dose $(\mathbf{m g})$ & $\begin{array}{c}\mathbf{C}_{\mathbf{s}}{ }^{\mathbf{g}} \\
\left(\mathbf{m g ~ m L} \mathbf{~ L}^{-1} \pm \times \mathbf{1 0}^{-\mathbf{2}}\right)\end{array}$ & $\mathbf{V}^{\mathbf{h}}(\mathbf{m L})$ & $\mathbf{D}_{\mathbf{0}}{ }^{\mathbf{i}}$ \\
\hline \multirow{2}{*}{ Diazepam } & 5 & $0.0385 \pm 0.011$ & 129.87 & 0.52 \\
& 10 & & 259.74 & 1.04 \\
\hline
\end{tabular}

g. $\mathrm{C}_{\mathrm{s}}$ - the saturation solubility of drug compound in aqueous medium at 37 ${ }^{\circ} \mathrm{C}$; h. V - volume of medium required to completely dissolving of dose, at minimum physiologic solubility; i. $\mathrm{D}_{\mathrm{o}}$ - dose number.

The lowest value of the physiological solubility of drug substance samples in the range of $\mathrm{pH}$ values of $1-7.5$ at $37^{\circ} \mathrm{C}\left(0.0385 \mathrm{mg} \mathrm{mL}^{-1}\right.$ at $\mathrm{pH} 7.4$, for micronized diazepam $)$ was taken as a reference value for the solubility of the substance. Value for volume, $250 \mathrm{~mL}$ was taken as the volume of water required to completely dissolve the minimum physiological solubility of the drug substance. Based on the calculated values, the ratio D : S (dose : solubility), for diazepam administered at a dose of 5 $\mathrm{mg}$ was less than $250 \mathrm{~mL}$. The required volume for the dissolution of a single dose of $10 \mathrm{mg}$ of diazepam was larger than $250 \mathrm{~mL}$. The active substance is considered to be poorly soluble if the D : S > $250 \mathrm{~mL}$. After calculation of dose number $\left(\mathrm{D}_{\mathrm{o}}\right)$ of diazepam (D1) at the dose of $5 \mathrm{mg}$ and $10 \mathrm{mg}$, it was observed that, diazepam administered at dose $5 \mathrm{mg}$ would be completely absorbed along whole GI tract, since the dose number was less than 1, which was not applicable to diazepam applied at the dose of $10 \mathrm{mg}$. In relation to the therapeutic dose of $10 \mathrm{mg}$ where $\mathrm{D}_{\mathrm{o}}$ was larger than 1 , with good permeability, diazepam could be classified in the BCS class II, whereas at dose of $5 \mathrm{mg}$, it belongs to the BCS class I. Class I drugs show rapid dissolution after the release from dosage forms, more than $85 \%$ dissolves in less than 15 minutes, providing a favorable bioavailability. Given that the value of $\mathrm{C}_{\mathrm{s}}$ diazepam (maximum solubility of diazepam in an aqueous medium of $\mathrm{pH} 7.4$ at $37^{\circ} \mathrm{C}$ ) was less than 0.05 $\mathrm{mg} \mathrm{mL} \mathrm{L}^{-1}$, the dissolution rate was limiting factor for the absorption after oral administration of the drug substance. The maximum ratio $\mathrm{D}: \mathrm{S}$ was $5 \mathrm{~mL}$ instead of $250 \mathrm{~mL}$, due to the volume of sputum, which is only $5 \mathrm{~mL}$, class I drugs in this case could be classified into class II $[5,11]$, so diazepam could be classified in the class II, applied in the given dose, considering that $\mathrm{D}: \mathrm{S}$ is reduced to the value of $\leq 5 \mathrm{~mL}$ (sputum).

\subsection{Content of Diazepam in Physical Mixtures and Inclusion Complexes}

Contents of diazepam in the sample A1 (physical mixture D : 2-HP- $\beta$-CD 1:1) was 99.91\% $\pm 0.642 \%$, A2 (physical mixture D : 2 -HP- $\beta$-CD 1:2) was $98.23 \% \pm 0.554 \%$, A 11 (inclusion complex D : 2-HP- $\beta-C D$ 1:1) was $99.77 \% \pm$ $0.557 \%$ and A21 (inclusion complex D : 2-HP- $\beta-C D$ 1:2) was $99.86 \% \pm 0.636 \%$. Based on the obtained results, the inclusion complexes formed by solvent evaporation, possessed sufficient content of diazepam, with a low standard deviation indicating content uniformity of diazepam in the given powders (relative standard deviation was less than $2 \%$ ).

\subsection{Solubility of Physical Mixtures and Inclusion

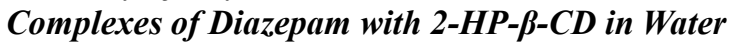

The mean absorbance, the concentration of dissolved binary physical mixtures $\left(\mathrm{S}_{\mathrm{CD}}\right)$ and inclusion complexes of diazepam with 2-HP- $\beta-\mathrm{CD}\left(\mathrm{S}_{\mathrm{CD}}\right)$ in water, the standard deviation $( \pm \mathrm{SD}, \mathrm{n}=3$ ) and solubility enhancement factor of diazepam $\left(\mathrm{S}_{\mathrm{D}}\right)$ after incorporation into the molecule 2-HP- $\beta$-CD were shown in Table 5.

\subsection{Solubility of Inclusion Complexes of Diazepam with 2-HP- $\beta-C D$ in Aqueous Buffer Solutions}

The results for inclusion complexes D : 2-HP- $\beta-C D$ solubility by changing the $\mathrm{pH}$ values of phosphate buffer solutions were summarized in Table 6 . 
Table 5. Solubility of binary physical mixtures and inclusion complexes of diazepam with $2-H P-\beta-C D$ in water at $37^{\circ} C \pm 0.1{ }^{\circ} \mathrm{C}$

\begin{tabular}{cccc}
\hline Sample & $\mathbf{A}^{\mathbf{b}}$ & Concentration of diazepam $\left(\mathbf{m g ~} \mathbf{~ m L}^{-\mathbf{1}} \pm \times \mathbf{1 0} \mathbf{0}^{-\mathbf{2}}\right)$ & $\mathbf{S}_{\mathbf{C D}} / \mathbf{S}_{\mathbf{D}}{ }^{\mathbf{j}}$ \\
\hline A1 & 0.3250 & $0.306 \pm 0.04$ & 7.29 \\
A2 & 0.4653 & $0.439 \pm 0.14$ & 10.36 \\
A11 & 0.4311 & $0.402 \pm 0.21$ & 9.57 \\
A21 & 0.3898 & $0.735 \pm 0.15$ & 17.49 \\
\hline
\end{tabular}

j. Solubility enhancement factor calculated as the ratio of solubility of physical mixtures in water $\left(\mathrm{S}_{\mathrm{CD}}, \mathrm{mg} \mathrm{mL}^{-1}\right)$, solubility of inclusion complexes in water $\left(\mathrm{S}_{\mathrm{CD}}, \mathrm{mg} \mathrm{mL}^{-1}\right)$ and solubility of non-micronized diazepam in water $\left(\mathrm{S}_{\mathrm{D}}, \mathrm{mg} \mathrm{mL}^{-1}\right)$ determined at temperature of $37^{\circ} \mathrm{C} \pm 0.1^{\circ} \mathrm{C}$

Tabela 6. Solubility of inclusion complexes of diazepam with 2-HP- $\beta-C D$

\begin{tabular}{|c|c|c|c|c|c|c|c|}
\hline \multicolumn{4}{|c|}{ D : 2-HP-ß-CD $1: 1$} & \multicolumn{4}{|c|}{$\mathrm{D}: 2-\mathrm{HP}-\beta-\mathrm{CD} 1: 2$} \\
\hline $\mathbf{p H}^{\mathrm{d}}$ & $\mathbf{A}^{\mathrm{b}}$ & $\begin{array}{c}\mathrm{D}^{\mathrm{c}} \\
\left(\mathrm{mg} \mathrm{mL}^{-1} \pm \times 10^{-2}\right)\end{array}$ & $\mathbf{S}_{\mathrm{CD}} / \mathbf{S}_{\mathbf{D}}{ }^{\mathbf{j}}$ & $\mathrm{pH}^{\mathrm{d}}$ & $\mathbf{A}^{\mathrm{b}}$ & $\begin{array}{c}\mathrm{D} 1^{\mathrm{c}} \\
\left(\mathrm{mg} \mathrm{mL}^{-1} \pm \times 10^{-2}\right)\end{array}$ & $\mathbf{S}_{\mathbf{C D}} / \mathbf{S}_{\mathbf{D}}{ }^{j}$ \\
\hline 1.2 & 0.4837 & $46.212 \pm 46.84$ & 906.12 & 1.2 & 0.3625 & $69.142 \pm 61.23$ & 1355.73 \\
\hline 2.0 & 0.5573 & $12.748 \pm 5.23$ & 249.96 & 2.0 & 0.6802 & $22.572 \pm 10.84$ & 442.59 \\
\hline 4.5 & 0.4580 & $0.427 \pm 0.22$ & 8.37 & 4.5 & 0.4120 & $0.780 \pm 0.92$ & 15.29 \\
\hline 5.5 & 0.4272 & $0.401 \pm 0.34$ & 7.86 & 5.5 & 0.3824 & $0.734 \pm 0.55$ & 14.39 \\
\hline 6.8 & 0.3734 & $0.348 \pm 0.27$ & 6.82 & 6.8 & 0.6756 & $0.640 \pm 0.44$ & 12.55 \\
\hline 7.4 & 0.6722 & $0.310 \pm 0.24$ & 6.08 & 7.4 & 0.6102 & $0.572 \pm 0.46$ & 11.22 \\
\hline
\end{tabular}

If the solubility of inclusion complexes of diazepam with 2-HP- $\beta$-CD 1:1 and 1:2 was expressed in descriptive terms, then the inclusion complexes were soluble at $\mathrm{pH} 1.2$, sparingly soluble at $\mathrm{pH} 2$, whereas at $\mathrm{pH} 4.5$ to 7.4 they were very slightly soluble. If the inclusion complexes were applied in therapeutic doses of $5 \mathrm{mg}$ and $10 \mathrm{mg}$ of diazepam, the absorption of active substances through the GI tract could be represented using the dose number $\left(D_{0}\right)$. Based on the calculated $D_{0}$, it was noted that the applied inclusion complex ratio $1: 1(1: 2)$ with a dose of $5 \mathrm{mg}$ of diazepam $(10 \mathrm{mg})$ could be completely absorbed along the GI tract, since the values of dose numbers were less than 1 $\left(4.5 \times 10^{-4}\right.$ to $6.5 \times 10^{-2}$ for D : 2-HP- $\beta$-CD $1: 1$; diazepam dose of $5 \mathrm{mg}$ ). Based on the solubility of the therapeutic dose of complexated diazepam with its good permeability, inclusion complexes of diazepam could be classified as class I according to the BCS classification of drugs.

In Table 7 . the effect of $2-\mathrm{HP}-\beta-\mathrm{CD}$, as complexing agent, was shown to increase the solubility of diazepam, reduce the dose number and reduce the volume of fluid required for complete dissolution of diazepam administered in a single dose of $10 \mathrm{mg}$.

It was observed that the complexation of diazepam with $2-\mathrm{HP}-\beta-\mathrm{CD}$ resulted in the dose number reduction to less than 1 , while the volume of water required for complete dissolution of diazepam in a single dose of $10 \mathrm{mg}$ was reduced to less than $250 \mathrm{~mL}$, or $\mathrm{D}: \mathrm{S}$ was $17.5 \mathrm{~mL}$ using 2 moles of $2-H P-\beta-C D$, but had not yet been reduced to a value of $\leq 5 \mathrm{~mL}$ (sputum) [24]. Since the Cs $>0.1-0.05 \mathrm{mg} \mathrm{mL}^{-1}$ of inclusion complexes, dissolution rate of complexated diazepam was not the limiting step for the absorption after oral application of diazepam (class I) [5].
Table 7. Calculated parameters for the individual dose complexed diazepam $10 \mathrm{mg}$

\begin{tabular}{|c|c|c|c|c|}
\hline Sample & $\begin{array}{c}\mathrm{C}_{\mathrm{s}} \\
\left(\mathrm{mg} \mathrm{mL}^{-1} \pm \times 10^{-2}\right)^{\mathrm{k}}\end{array}$ & $\sigma^{1}$ & $\mathbf{V}(\mathbf{m L})^{\mathrm{m}}$ & $D_{0}{ }^{i}$ \\
\hline D : 2-HP- $\beta-C D ~ 1: 1$ & $0.310 \pm 0.248$ & 8.05 & 32.26 & 0.13 \\
\hline D : 2 -HP- $\beta-C D ~ 1: 2$ & $0.572 \pm 0.462$ & 14.86 & 17.48 & 0.07 \\
\hline
\end{tabular}

k. $\mathrm{C}_{\mathrm{s}}$ - the saturation solubility of drug compound in aqueous medium at 37 ${ }^{\circ} \mathrm{C} \pm 0.1{ }^{\circ} \mathrm{C} ; 1 . \sigma$ - solubility enchancement of diazepama in the presence of 2-HP- $\beta$-CD; $\mathrm{m}$. V - volume of medium required to completely dissolving the $10 \mathrm{mg}$ dose, at minimum physiologic solubility.

\subsection{Determination of Residual Methanol in the Inclusion Complexes with 2-HP- $\beta$-CD}

Evaporation of methanol from the inclusion complexes was carried out at $40{ }^{\circ} \mathrm{C} \pm 0.5{ }^{\circ} \mathrm{C}$, while drying of the samples in the vacuum oven, in order to remove residual solvent, was performed at $40{ }^{\circ} \mathrm{C} \pm 0.5^{\circ} \mathrm{C}$ and $75^{\circ} \mathrm{C} \pm 0.5^{\circ} \mathrm{C}$. The presence of residual solvent in the inclusion complexes D : 2-HP- $\beta$-CD 1:1 and D : 2-HP- $\beta$-CD 1:2 was determined by gas chromatography. The mean peak areas of standard solutions and test solutions were given in Table 8, as well as the calculated concentrations of methanol in the samples, expressed in ppms

The usual maximum daily dose of diazepam is $40 \mathrm{mg}$ and in exceptional cases it can be up to $60 \mathrm{mg}$. The value of 60 mg of diazepam was taken as permitted daily exposure (PDE). Based on Eq. 3, limited concentration of methanol was $84033.6 \mathrm{ppm}$, for the inclusion complex D: $2-\mathrm{HP}-\beta-\mathrm{CD}$ $1: 1$, while for the D: $2-H P-\beta-C D 1: 2$ limited concentration of methanol was $45857.53 \mathrm{ppm}$. The temperature of $40^{\circ} \mathrm{C}$ used during the drying of the sample in vacuum oven was sufficient for the evaporation of methanol to the concentrations (ppm) that are nontoxic to a patient. The 
temperature of $75{ }^{\circ} \mathrm{C}$ for the evaporation of methanol in vacuum oven was the ideal temperature, leaving the minimum residue of methanol in the powder $\left(3.6 \times 10^{-4} \%\right.$ and $3.8 \times 10^{-4} \%$ ), compared to a maximum daily dose of diazepam, while on the other hand, the mentioned temperature did not affect the thermostability of diazepam, whose melting point is $134.7^{\circ} \mathrm{C}$.

\subsection{Determination of Particle Size Distribution of Inclusion Complexes of Diazepam with 2-HP- $\beta-C D$}

Results of particle size distribution for the inclusion complexes of diazepam and 2-hydroxypropyl- $\beta$-cyclodextrin in molar ratios of 1:1 (D: 2-HP- $\beta-C D \quad 1: 1$ ) and 1:2 (D: 2-HP- $\beta-C D$ 1:2), were presented numerically (Table 9) and graphically in Fig. 6 and 7.

Table 8. Concentrations of residual solvent in the inclusion complexes of diazepam with D : 2-HP- $\beta-C D$

\begin{tabular}{|c|c|c|c|c|}
\hline \multirow[b]{2}{*}{ Sample } & \multicolumn{4}{|c|}{ Parameters } \\
\hline & Peak area & $\begin{array}{l}\text { Mass of the test substance } \\
\text { (mg) }\end{array}$ & $\begin{array}{c}\text { Concentration of methanol (ppm) } \\
\left(40^{\circ} \mathrm{C}\right)\end{array}$ & $\begin{array}{c}\begin{array}{c}\text { Concentration of methanol } \\
(\mathrm{ppm})\left(75^{\circ} \mathrm{C}\right)\end{array} \\
\end{array}$ \\
\hline Diazepam standard & 974484.24 & 62.50 & - & - \\
\hline D : 2-HP- $\beta-C D ~ 1: 1$ & 12966659.57 & 1000.53 & 6642.915 & - \\
\hline D : 2-HP- $\beta-C D ~ 1: 2$ & 12604284.57 & 1001.15 & 6453.268 & - \\
\hline D : 2-HP- $\beta-C D ~ 1: 1$ & 7108.05 & 1001.40 & - & 3.638 \\
\hline D : 2-HP-ß-CD 1: 2 & 7515.49 & 1001.00 & - & 3.848 \\
\hline
\end{tabular}

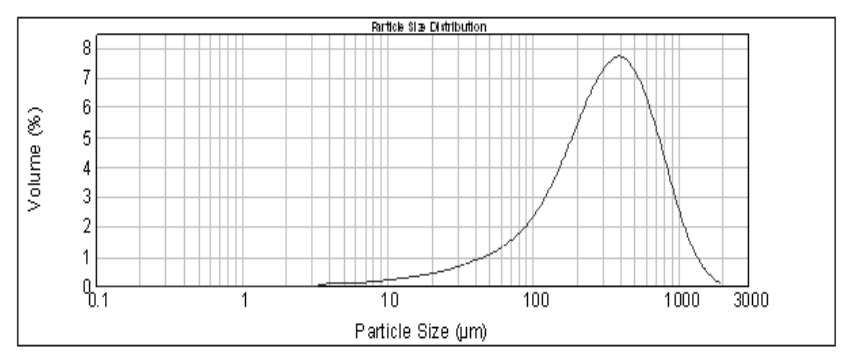

Figure 6. Particle size distribution of inclusioncomplex $D$ : 2-HP- $\beta-C D$ 1:1

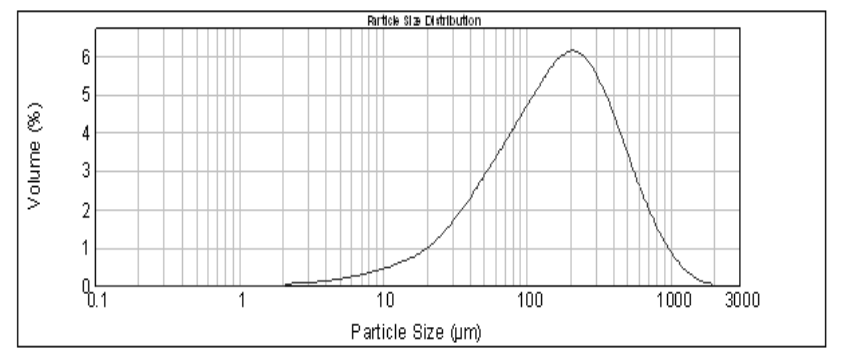

Figure 7. Particle size distribution of inclusion complex $D$ : 2-HP- $\beta-C D$ $1: 2$

Based on the results of particle size distribution of the inclusion complex D : 2-HP- $\beta$-CD 1:1, it was observed that $90 \%$ of particles were less than $785.5 \mu \mathrm{m}$ in diameter. Ninety percent of the particulate inclusion complex D : 2-HP- $\beta-C D$ 1:2 had particle size less than 518.1 $\mu \mathrm{m}$. Powders of inclusion complexes of diazepam with $2-\mathrm{HP}-\beta-\mathrm{CD}$ were crystalline, white powders, very easily handled compared to the micronized diazepam powder. Prepared inclusion complexes were designed for the production of orodisperzible tablets of diazepam. It could be assumed that the powders of inclusion complexes would have better flowability compared to micronized diazepam, because they have larger powder particles with size exceeding $500 \mu \mathrm{m}$.
Powder flow rate increases with increasing particle size. With increasing the particle size, up to about $1000 \mu \mathrm{m}$, according to Carr-in, the flowability is increased, and with further increasing the particle size of the powder, the flowability decreases. Too large particles can create a problem in tablet production (dispenser blockage, disruption of the flow of powder into matrix tabletting machines, etc.) [26]. Flow rate of powder increases the removal of particles smaller than $10 \mu \mathrm{m}$. Excessive fragmentation leads to the formation of very fine particles that can obstruct the flow of adhesive particles or create an electrostatic charge. In tablet production, micronized powders may exhibit difficulty when mixed with the other excipients, and for the same reason can cause non-uniform tablet content. With regards to the distribution of particle size, the flow rate of powder inclusion complex D : 2-HP- $\beta$-CD 1:1 was higher compared to the powder inclusion complex D : 2-HP- $\beta$-CD 1:2. In addition, the inclusion complex D : 2-HP- $\beta-C D$ 1:1 had larger particles, and even the smaller particles $\mathrm{d}(0.1)-75.5$ $\mu \mathrm{m}, \mathrm{d}(0.5)-318.9 \mu \mathrm{m})$ were still larger than the particles of the complex D : 2-HP- $\beta$-CD 1:2 (d (0.1) - $34.3 \mu \mathrm{m}, \mathrm{d}(0.5)$ $163.1 \mu \mathrm{m})$.

\subsection{Determination of Intrinsic Dissolution Rates of Diazepam and Inclusion Complexes of Diazepam with 2-HP-B-CD Using a Rotating Disk Method}

The intrinsic dissolution rates of diazepam: D1 micronized diazepam, D2 - non-micronized diazepam, and inclusion complexes D: $2-\mathrm{HP}-\beta-\mathrm{CD} 1: 1$ and D: $2-\mathrm{HP}-\beta-\mathrm{CD}$ $1: 2$ were investigated. The mean concentrations of dissolved diazepam $\left(\mathrm{mg} \mathrm{mL}^{-1}\right)$, for all four powders $(\mathrm{n}=6)$ were given in Table 10. The dissolution rate of the tested samples were shown on Fig 8, where the phosphate buffer solution $\mathrm{pH} 6.8$ was used as a dissolution medium. 
Tabela 9. Particle size distribution of inclusion complexes

\begin{tabular}{|c|c|c|c|c|}
\hline \multirow{2}{*}{ Samples } & \multirow{2}{*}{ Specific surface area $\left(\mathrm{m}^{2} \mathrm{~g}^{-1}\right)$} & \multicolumn{3}{|c|}{ Particle size distribution of inclusion complex } \\
\hline & & $\mathrm{d}(0.1)^{\mathrm{a}} \mu \mathrm{m}$ & $\mathrm{d}(0.5)^{\mathrm{b}} \mu \mathrm{m}$ & $\mathrm{d}(0.9)^{\mathrm{c}} \mu \mathrm{m}$ \\
\hline D : 2-HP- $\beta$-CD $1: 1$ & 0.0447 & 75.533 & 318.856 & 785.513 \\
\hline D : 2 -HP- $\beta$-CD $1: 2$ & 0.0868 & 34.291 & 163.133 & 518.111 \\
\hline
\end{tabular}

Table 10. Concentrations of dissolved diazepam from comprimates of tested samples

\begin{tabular}{|c|c|c|c|c|}
\hline \multirow{2}{*}{$\begin{array}{c}\text { Time } \\
\text { (minute) }\end{array}$} & \multicolumn{4}{|c|}{ Concentration of diazepam $\left(\times 10^{-3} \mathrm{mg} \mathrm{mL}^{-1} \pm \times 10^{-3}\right)$} \\
\hline & D1 & D2 & D : 2-HP- $\beta$-CD 1:1 & D : 2-HP- $\beta-C D ~ 1: 2$ \\
\hline 0 & $0.000 \pm 0.00$ & $0.000 \pm 0.00$ & $0.000 \pm 0.00$ & $0.000 \pm 0.00$ \\
\hline 5 & $0.092 \pm 1.04$ & $0.069 \pm 0.86$ & $0.464 \pm 1.54$ & $3.604 \pm 28.85$ \\
\hline 10 & $0.109 \pm 1.33$ & $0.082 \pm 0.67$ & $0.645 \pm 2.93$ & $4.007 \pm 49.05$ \\
\hline 15 & $0.123 \pm 0.95$ & $0.091 \pm 1.48$ & $0.821 \pm 5.49$ & $4.500 \pm 43.54$ \\
\hline 20 & $0.137 \pm 0.84$ & $0.102 \pm 0.25$ & $1.020 \pm 7.19$ & $4.975 \pm 39.31$ \\
\hline 25 & $0.148 \pm 0.86$ & $0.116 \pm 0.83$ & $1.187 \pm 1.11$ & $5.479 \pm 45.21$ \\
\hline 30 & $0.160 \pm 0.78$ & $0.130 \pm 0.94$ & $1.302 \pm 9.35$ & $6.358 \pm 31.55$ \\
\hline 35 & $0.171 \pm 0.90$ & $0.141 \pm 0.38$ & $1.382 \pm 7.02$ & $6.485 \pm 28.06$ \\
\hline 40 & $0.181 \pm 0.78$ & $0.154 \pm 1.08$ & $1.473 \pm 8.36$ & $6.665 \pm 51.74$ \\
\hline 45 & $0.194 \pm 1.00$ & $0.171 \pm 1.22$ & $1.562 \pm 4.05$ & $6.810 \pm 62.39$ \\
\hline 50 & $0.207 \pm 0.87$ & $0.181 \pm 0.94$ & $1.634 \pm 9.13$ & $6.864 \pm 81.02$ \\
\hline 55 & $0.217 \pm 1.06$ & $0.194 \pm 1.02$ & $1.697 \pm 7.75$ & $7.025 \pm 77.28$ \\
\hline 60 & $0.228 \pm 1.34$ & $0.207 \pm 1.64$ & $1.787 \pm 9.73$ & $7.095 \pm 67.85$ \\
\hline $\begin{array}{c}\text { IDR } \times 10^{-3} \\
\left(\mathrm{mg} \mathrm{min}^{-1} \mathrm{~cm}^{-2}\right)\end{array}$ & 5.04 & 4.14 & 65.52 & 169.92 \\
\hline $\mathrm{R}^{2}$ & 0.995 & 0.992 & 0.999 & 0.999 \\
\hline
\end{tabular}

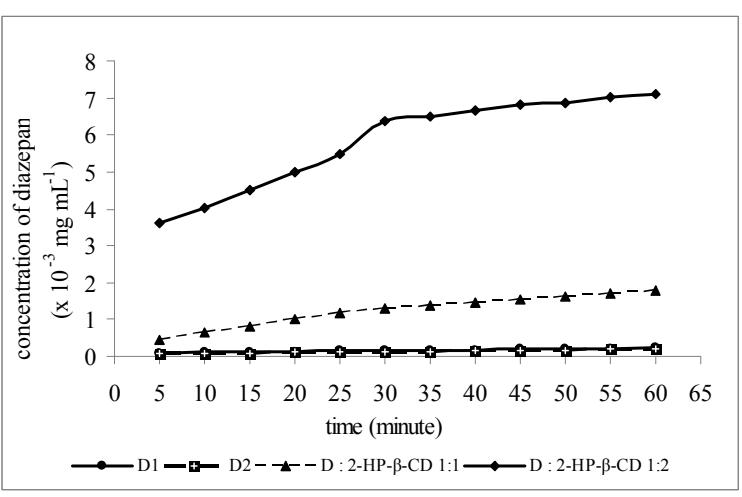

Figure 8. Concentracion of dissolved diazepam from comprimates of tested samples.

Intrinsic dissolution rate of tested powders was calculated by linear regression analysis, from the slope of the regression curve. To calculate the intrinsic dissolution rate, the concentrations of dissolved diazepam in the time interval of 5 to 25 minutes were used. Dependence of dissolved diazepam on time was linear in the specified interval, in all tested powders. For all tested samples correlation coefficient values between $0.990-0.999\left(\mathrm{R}^{2}>0.990\right)$ were achieved, so that any other two values, except zero time could be taken. Intrinsic dissolution rates of tested diazepam samples in phosphate buffer solution $\mathrm{pH} 6.8$ were similar, while the value of the IDR of micronized diazepam increased 1.22 fold compared to non-micronized diazepam. Intrinsic dissolution rate of micronized diazepam had increased over time due to small particles of powder compared to the particle size of the powder of non-micronized diazepam. Intrinsic dissolution rate (IDR or $j$ ) of inclusion complex D: 2 -HP- $\beta$-CD 1:1 was higher 13 fold, compared to the IDR of micronized diazepam or 15.83 fold, compared to the IDR of non-micronized diazepam. IDR was the largest for the inclusion complex D: 2-HP-3-CD 1:2, which was higher 33.71 and 41.04 fold compared to micronized or non-micronized diazepam, respectively. The IDR value of this complex was 2.59 fold higher than the IDR value of inclusion complex D: 2-HP- $\beta$-CD 1:1. So, intrinsic dissolution rate was significantly higher when diazepam was used to form complexes with $2-\mathrm{HP}-\beta-\mathrm{CD}$, especially when two moles of cyclodextrin were employed. Since the IDR values for micronized diazepam, non-micronized diazepam and for inclusion complex D: 2-HP- $\beta-C D$ 1:1 were less than $0.1 \mathrm{mg}$ $\min ^{-1} \mathrm{~cm}^{-2}$, it could be concluded that drug dissolution would be the rate-limiting step to absorption [13], while the IDR-value of inclusion complex D: 2-HP- $\beta-C D$ 1:2 was greater than $0.1 \mathrm{mg} \mathrm{min}^{-1} \mathrm{~cm}^{-2}$, leading to the conclusion that diazepam dissolution might be the rate-limiting step to absorption of diazepam.

Drug dissolution is the rate-limiting step to absorption when the intrinsic dissolution rate of substance is less than $0.1 \mathrm{mg} \mathrm{min}{ }^{-1} \mathrm{~cm}^{-2}$, usually meaning that its solubility is less than $1 \mathrm{mg} \mathrm{mL}^{-1}$. Under certain conditions, dissolution rate and solubility are proportional. Absorption is unobstructed when the intrinsic dissolution rate is greater than $1 \mathrm{mg} \mathrm{min}^{-1}$ $\mathrm{cm}^{-2}$ [24]. Intrinsic dissolution rate of micronized diazepam was $5.04 \times 10^{-3} \mathrm{mg} \mathrm{min}^{-1} \mathrm{~cm}^{-2}$, while the solubility of micronized diazepam was $0.043 \mathrm{mg} \mathrm{mL}^{-1}$, at $\mathrm{pH} 6.8$, at $37^{\circ} \mathrm{C}$ $\pm 0.1{ }^{\circ} \mathrm{C}$. It was evident that there was a good quantitative correlation between the classification of diazepam based on 
the obtained solubility and IDR values. Comparing the solubility of diazepam in an aqueous medium of $\mathrm{pH} 6.8$ to IDR values at the same $\mathrm{pH}$ and the same temperature, diazepam was classified as drug substance of low solubility, or according to BCS classification of drug, it was classified into class II, which will probably show that the dissolution is the rate-limiting step to absorption[27].

\section{Conclusion}

It takes about twenty hours to reach aqueous saturation of diazepam, so that 24 hours is sufficient period of time for the solubility tests of complexated diazepam. Diazepam is almost insoluble substance in water, which was confirmed by the fact that the dissolution of its highest dose at $\mathrm{pH}$ values in the range of $1-7.4$ at $37{ }^{\circ} \mathrm{C}$ required volume greater than $250 \mathrm{~mL}$ of water or a suitable aqueous medium, and according to BCS classification of drugs, it ranks in the class II. The particle size of the powder affects the solubility of diazepam in water, so that the micronized diazepam (D1 $90 \%$ of particles less than $5.4 \mu \mathrm{m}$ ) had greater solubility in water compared to powder of non-micronized diazepam (D2 - 90\% of particles smaller than $414.8 \mu \mathrm{m}$ ). Hydrophobic surface area of diazepam increased with decreasing particle size (micronization) and hindered wetting of the powder in water. Diazepam, as weakly dissociating base, at lower $\mathrm{pH}$ values of the media significantly dissociates, and at $\mathrm{pH} 6.8$ more than $99.94 \%$ is found in non-ionized form, or less than $0.06 \%$ in dissociated form, thus good absorption through the buccal mucosa of diazepam could be expected. The preparation of inclusion complexes of diazepam with 2-HP- $\beta$-CD justified the application of methanol (class 2 solvent) since with its evaporation at $40{ }^{\circ} \mathrm{C}$, especially at $75^{\circ} \mathrm{C}$, the residues of the solvents in concentrations toxic to the patient were not found. Solvent evaporation method resulted in the inclusion complexes with uniform content. Diazepam complexated with $2-\mathrm{HP}-\beta-\mathrm{CD}$, administered in dose of $5 \mathrm{mg}$, with good permeability (in the range of $1-10$ $\times 10^{-4} \mathrm{~cm} \mathrm{~s}^{1}$ ), could be classified into class I of the BCS classification of drugs, since a given dose is "highly soluble" through the entire GI tract.

Powders of inclusion complexes of diazepam with 2-HP- $\beta-C D$ were very easy to handle compared to the diazepam micronized powder, due to its larger powder particles exceeding $500 \mu \mathrm{m}$. Particle size is fundamental to avoiding problems when mixing with the other excipients, given their better flow rate in the preparation of tablets, thus achieving uniformity of content of the finished product. If the solubility of diazepam in an aqueous medium of $\mathrm{pH} 6.8$ was compared to IDR values at the same $\mathrm{pH}$, diazepam could be classified as a drug of low solubility, or according to the BCS classification of drugs into class II, which would likely show problems in the absorption rate due to the limited dissolution rate. Given that the values of the intrinsic dissolution rate of micronized diazepam, the non-micronized diazepam and for the inclusion complex D: 2-HP- $\beta$-CD 1:1 were less than $0.1 \mathrm{mg} \mathrm{min}^{-1} \mathrm{~cm}^{-2}$, dissolution would be the rate-limiting step to absorption, while IDR-value of the inclusion complex D: $2-\mathrm{HP}-\beta-\mathrm{CD} 1: 2$ was greater than $0.1 \mathrm{mg} \mathrm{min}^{-1} \mathrm{~cm}^{-2}$, thus it would probably show dissolution to be the rate-limiting step to absorption of diazepam. IDR can be used to classify drugs instead of solubility. The quantity of material required to carry out this test is much smaller, than what is required for the solubility test. Since this test is not related to equilibrium, but rather to the dissolution rate, there is expected to be a greater correlation in the in vivo dissolution dynamics, than with the solubility test.

\section{References}

[1] R. Mandrioli, L. Mercolini, M. A. Raggi, Benzodiazepine metabolism: an analitycal perspective, Curr Drug Metab, 2008, 9, 827-844.

[2] J. Riss, J. Cloyd, J. Gates, S. Collins, Benzodiazepines in epi lepsy: pharmacology and pharmacokinetics, Acta Neurol Scand, 2008, 118, 69-86.

[3] K. Mehta, K. Garala, B. Basu, R. Bhalodia, B. Joshi, R. N. Charyulu, An emerging trend in oral drug delivery technology: rapid disintegrating tablets, J Pharm Sci Technol, 2010, 2, 318-329.

[4] T. G. Kumar, B. Sa, Preparation and evaluation of rapidly disintegrating fast release tablet of diazepam-hydroxypropyl- $\beta$-cyclodextrin inclusion complex, Pharmacology and Pharmacy, 2010, 1, 18-26.

[5] T. Loftsson, M. E. Brewster, M. Másson, Role of cyclodextrins in improving oral drug delivery, Am J Drug Deliv, 2004, 2, 261-275.

[6] G. Mosher and D. O. Thompson, "Complexation: Cyclodextrins," in Encyclopedia of pharmaceutical technolo gy, 3rd ed., J. Swarbrick, Ed. New York: Informa Healthcare, 2007, pp. 671-696

[7] M. E. Brewster, T. Loftsson, Cyclodextrins as pharmaceutical solubilizers, Adv Drug Deliv Rev, 2007, 59, 645-666.

[8] Guidance for industry: waiver of in vivo bioavailability and bioequivalence studuies for immediate-release solid oral dosage forms based on a biopharmaceutical classification system, U.S. department of health and human services, food and drug administration (FDA), center for drug evaluation and reasearch (CDER), 2000, pp.1-13.

[9] M. P. Wagh, J. S. Patel, Biopharmaceutical classification sys tem: scientific basis for biowaiver extensions, Inter J Pharm Pharm Sci, 2010, 2, 12-19.

[10] M. G. Issa, H. G. Ferraz, Intrinsic dissolution as a tool for evaluating drug solubility in accordance with the biopharmaceutics classification system, Dissolution Tech nologies, 2011, 18, 6-13.

[11] A. Dahan, J. M. Miller, G. L. Amidon, Prediction of solubility and permeability class membership: provi sional BCS classification of the world's top oral drugs, AAPS, 2009, 11, 740-746.

[12] V. M. Varma, S. Khandavilli, Y. Ashokraj, A. Jain, A. 
Dhanikula, A. Sood, S. N. Thomas, O. Pillai, P. Sharma, R. Gandhi, S. Agrawal, V. Nair, R. Panchagnula, Bio pharmaceutical classification system: a scientific frame work for pharmacokinetic optimization in drug research, Curr Drug Metab, 2004, 5, 375-388.

[13] A. M. Dyas and U. U. Shah, "Dissolution and dissolution testing," in Encyclopedia of pharmaceutical technology, 3rd ed., J. Swarbrick, Ed. New York: Informa Healthcare, 2007, pp. $908-928$.

[14] L. X. Yu, A. S. Carlin, G. L. Amidon, A. S. Hussain, Feasi bility studies of utilizing disk intrinsic dissolution rate to classify drugs, Int J Pharm, 2004, 270, 221-227.

[15] B. Y. Wang and O. R. Williams III, „Powders,“ in Remington The science and practice of pharmacy, 22nd ed., L. A. Loyd, Ed. London, Philadelphia: Pharmaceutical Press, 2013, pp. 777-798.

[16] K. P. Gupta, „Solutions and phase equilibrria, “ in Remington The science and practice of pharmacy, 22nd ed., L. A. Loyd, Ed. London, Philadelphia: Pharmaceutical Press, 2013, pp. 588-590.

[17] J. Parasrampuria, "Liquid oral preparations," in Encyclope dia of pharmaceutical technology, vol. 9., J. Swarbrick and J. C. Boylan, Eds.: New York, Basel, Hong Kong: Marcel Dekker Inc., 1994, pp. 41-59.

[18] M. Gibaldi, S. Feldman, Establishment of sink conditions in dissolution rate determinations, theoretical considerations and application to nondisintegrating dosage forms, J Pharm Sci, 1967, 56, 1238-1242.

[19] R. Agarwal, V. Gupta, Cyclodextrins - a review on pharma ceutical application for drug delivery, Inter J Pharm Frontier Res, 2012, 2, 96-113.
[20] A. A. N. Lima, J. L. S. Sobrinho, R. A. C. Corrêa, P. J. Neto Rolim, Alternative technologies to improve solubility of poorly water soluble drugs, Lat Am J Pharm, 2008, 27, 789-797.

[21] ICH topic Q3C (R4) impurities: guideline for residual sol vents, center for drug evaluation and research (CDER), step 5, 2009, pp.1-22.

[22] Council of Europe, The European pharmacopoeia, 7th ed., vol. 2., European directorate for the quality of medicine (EDQM), Strasbourg, 2011, pp. 295-295.

[23] V. Kumar and P. Hiremath, „Dissolution,“ in Remington The science and practice of pharmacy, 22nd ed., L. A. Loyd, Ed. London, Philadelphia: Pharmaceutical Press, 2013, pp. 435-436.

[24] J. I. Wells and M. E. Aulton, "Preformulation," in Pharma ceutics The science of dosage form design, 2nd ed., E. M. Aulton, Ed., Edinburgh, etc.: Churchill Livingstone, 2001, pp. 224-252.

[25] J. D. Higgins, W. L. Rocco, A stop along the drug development highway. Today`s chemist at work, 2003, 12, 22-26.

[26] S. A. Howard, "Flow properties of solids," in Encyclopedia of pharmaceutical technology, 2th ed., vol. 2., J. Swarbrick and J. C. Boylan, Eds. New York, Basel: Marcel Dekker Inc., 2002, 1264-1271.

[27] E. G. Granero, C. Ramachandran and G. L. Amido, "Gastrointenstinal dissolution and absorption of drug," in Drug bioavability: estimination of solubility, permeability, absorption and bioavailability, vol. 18. H. van de Waterbeemd Lennernäs and P. Arturrson, Eds. Weisenheim: Wiley-VCH, 2003, pp. 191-210. 